\title{
Comprendre l'obésité
}

\section{Grangeard \\ (C) Springer-Verlag France 2012}

L'obésité, en augmentation croissante, apparaît aujourd'hui comme un phénomène de société. Pourtant, la réponse habituelle apportée à cette énigme se limite trop souvent à être individuelle. Or, comme l'explique Catherine Grangeard - psychanalyste et membre de réseaux de prise en charge des personnes obèses (Fig. 1) -, il s'agit d'une pathologie plurifactorielle, voire multiple, car il existe plusieurs types d'obésités.

À travers une série de cas très représentatifs, de tous les âges et de tous les milieux, cet essai illustre comment le rapport à l'alimentation traduit la relation à soi et au monde.
L'individu obèse étant avant tout un être social, sensible à son environnement et à sa culture, bien d'autres éléments sont donc à prendre en compte.

Ce livre est utile pour tous ceux qui sont concernés par l'excès de poids, personnellement ou professionnellement, il est aussi un outil pédagogique. Comprendre comment le psychique et le somatique s'articulent permet de s'écarter du symptôme pour s'intéresser au sujet, à son histoire, à sa parole.

L'auteur s'adresse ici tant aux enfants qu'aux adultes, enfermés dans des répétitions parce que le problème est ailleurs. Il s'agit d'en saisir les origines pour s'en débarrasser...

Car se limiter à la question de l'alimentation compromet inéluctablement les projets de perte de poids, même quand la meilleure volonté les accompagne.

C. Grangeard $(\bowtie)$

115 , rue de la République, 78650 Beynes

e-mail : catherine.grangeard@wanadoo.fr 